\title{
EFEITOS DA CALAGEM E DA ADUBAÇÃO POTÁSSICA SOBRE CARACTERÍSTICAS AGRONÔMICAS E PROPRIEDADES TECNOLÓGICAS DA FIBRA DO ALGODOEIRO $\left({ }^{1}\right)$
}

\author{
NELSON PAULIERI SABINO $\left({ }^{2,6}\right)$, JULIO ISAO KONDO $\left({ }^{2}\right)$, \\ NELSON MACHADO DA SILVA $\left({ }^{3,6}\right)$, JOSÉ CARLOS SABINO $\left({ }^{4}\right)$ e TOSHIO IGUE $\left({ }^{5}\right)$
}

\begin{abstract}
RESUMO
Em latossolo roxo, ácido e de baixa fertilidade, do município de Guaíra (SP), implantou-se, em 1976, um ensain permanente de calagem e adubação potássica com o algodoeiro, variedade IAC 18. Em esquema de parcelas subdivididas, o calcário dolomítico foi incorporado às parcelas nas doses de $0,2,4$ e $6 \mathrm{t} / \mathrm{ha}$ no primeiro ano. O potássio foi aplicado anualmente, nas doses de $0,50,100 \mathrm{e} 150 \mathrm{~kg} / \mathrm{ha}$ de $\mathrm{K}_{2} \mathrm{O}$, na forma de cloreto e na presença de doses constantes de $\mathrm{N}, \mathrm{P}_{2} \mathrm{O}_{5}$ e, quando necessário, boro. No sexto ano (1981/82), reaplicou-se o calcário nas doses originais e, nos anos subseqüentes até 1985/86, utilizou-se a variedade IAC 20. No primeiro ciclo de calagem, o calcário alterou positivamente a massa de um capulho e deprimiu a de cem sementes. Ambas as características foram beneficiadas pela adubação potássica. Quanto às propriedades tecnológicas da fibra, o comprimento, a maturidade, o índice Micronaire e a tenacidade diminuíram com a calagem, enquanto a adubação potássica proporcionou melhoria apenas à uniformidade de comprimento e índice Micronaire. A porcentagem de fibra nāo foi afetada pela calagem e teve seus valores diminuídos pela ação do potássio. Os resultados do segundo ciclo de calagem confirmaram o efeito positivo do calcário sobre a massa de um capulho e da adubação potássica nessa característica e também na massa de cem sementes. Verificou-se, ainda, efeito depressivo do corretivo na porcentagem de fibra. Quanto às propriedades tecnológicas da fibra, a calagem se mostrou tão prejudicial como na primeira fase, enquanto o
\end{abstract}

(1) Trabalho apresentado na IV Reunião Nacional do Algodão, Belém (PA), 1986. Recebido para publicação em 22 de novembro de 1994 e aceito em 30 de agosto de 1995.

(2) Seção de Tecnologia de Fibras, Instituto Agronômico (IAC), Caixa Postal 28, 13001-970 Campinas (SP).

$\left({ }^{3}\right)$ Seção de Algodão, IAC.

(4) Estação Experimental de Tietê, IAC.

(5) Seção de Técnica Experimental e Cálculo, IAC.

$\left({ }^{6}\right)$ Com bolsa de pesquisa do $\mathrm{CNPq}$. 
uso do potássio continuou concorrendo para aumentar a uniformidade de comprimento, o índice Micronaire e a maturidade da fibra. Essa prática deprimiu os valores de tenacidade da fibra. Em nenhum dos dois ciclos, verificou-se interação entre calagem e adubação potássica.

Termos de indexação: algodāo, fibra, características agronômicas, propriedades tecnológicas, calagem, adubação potássica.

\section{ABSTRACT \\ EFFECTS OF LIMING AND POTASSIUM FERTILIZATION ON THE AGRONOMIC CHARACTERISTICS AND TECHNOLOGICAL PROPERTIES OF THE COTTON FIBER}

The effects of liming and potassium fertilization on the agronomic characteristics and technological properties of the cotton fiber were studied in a permanent trial on a Dystrophic Dusky Red Latosol, acid, of low fertility during growing seasons of 1976/77 to 1985/86. A split-plot design was used, dolomitic limestone being applied on the plots at the levels of $0,2,4$ and $6 \mathrm{t} / \mathrm{ha}$, while the doses of 0,50 , 100 and $150 \mathrm{~kg} / \mathrm{ha}$ of $\mathrm{K}_{2} \mathrm{O}$, corresponded to the subplots. Lime was applied in the first year, and the experiment was conducted and reapplicated during 1981/82, while potassium was furnished annualy, at planting time, in mixture with NK fertilizers. Liming caused an increase in the mass of bolls and reduced the mass of seed, length, length uniformity, Micronaire index, maturity and fiber strength. Potassium fertilization caused an increase in mass of bolls and seeds, length uniformity, Micronaire index, maturity and fiber strength, when was applied, on the last, the correction of the Pressley values. Anyone interaction between lime and potassium was observed.

Index terms: cotton, fiber quality, agronomic characteristics, technological properties, liming, potassium fertilization.

\section{INTRODUÇÃO}

Sabe-se que em culturas exigentes, como o algodoeiro, o uso exclusivo de calcário não oferece possibilidades de sucesso, a não ser que se trate de solos bem providos de elementos minerais, cujo fator limitante é a acidez. Por via de regra, a calagem deve ser acompanhada de adubações adequadas, do contrário seu efeito pode ser de pouco ou nenhum valor (Fuzatto, 1965).

Diante do exposto e com base na revisão de literatura realizada por Silva (1983), verificou-se que, a despeito de se estudar a correçăo da acidez do solo para a cultura do algodoeiro desde meados de 1930, no Estado de São Paulo, são poucos os dados sobre sua influência na qualidade do produto. Fuzatto et al. (1965) citam resultados de ensaio de longa duração, em solo ácido, onde o uso da calagem beneficiou a massa de um capulho e de cem sementes e a porcentagem de fibras. Tais observações foram relatadas também por Carvalho (1980), quando realizou estudos em solos com acidez parcialmente corrigida (5,7 de $\mathrm{pH}$, em água). Quanto às propriedades tecnológicas da fibra, segundo Sabino (1973), o uso de calcário parece não modificar sensivelmente o comprimento, a uniformidade de comprimento e a tenacidade das fibras, enquanto concorre para depreciar o índice Micronaire.

A aplicação de potássio no algodoeiro tem mostrado resultados contraditórios no que se refere à sua influência sobre as características agronômicas e as propriedades tecnológicas da fibra. Assim, Christidis \& Harrison (1955), Schimidt et al. (1962) e Silva et al. (1974) não verificaram efeito sobre a massa de um capulho em função da adubação 
potássica. Por outro lado, Neves et al. (1960), Fuzatto et al. (1965) e Silva et al. (1974) obtiveram resultados apreciáveis para essa característica, quando o adubo foi utilizado em solos progressivamente mais carentes. Com relação às propriedades tecnológicas da fibra, Nelson (1949), Neves et al. (1960), Silva et al. (1971, 1974), Sabino (1973), e Sabino et al. (1984) verificaram que o uso do potássio, quando em condições de deficiência do nutriente, concorre para melhorar a uniformidade de comprimento, o índice Micronaire e a maturidade da fibra, não exercendo nenhum efeito sobre o comprimento e, em alguns casos, deprime a tenacidade.

Objetivando estudar os cfcitos da calagem e adubação potássica sobre as características agronômicas e as propriedades tecnológicas da fibra do algodoeiro, utilizaram-se os resultados anuais de um ensaio de caráter permanente, instalado em 1976/77-1985/86, em solo ácido e pobre em potássio.

\section{MATERIAL E MÉTODOS}

Aplicando-se os resultados de ensaio permanente de calagem e adubação potássica, desenvolvido anualmente em Guaíra (SP), a partir do ano agrícola 1976/77, em latossolo roxo, distrófico, ácido e pobre em potássio para a cultura algodoeira, avaliou-se o efeito dessas duas práticas sobre as características agronômicas e propriedades tecnológicas da fibra do algodão.

O plano experimental constou de dezesseis tratamentos com quatro repetições, em um esquema de parcelas subdivididas com distribuição em blocos ao acaso. O calcário foi incorporado às parcelas nas doses de $0,2,4$ e 6 t/ha, no primeiro ano de estudo, e o adubo potássico, aplicado anualmente, ocupou as subparcelas nas doses de $0,50,100 \mathrm{e}$ $150 \mathrm{~kg} / \mathrm{ha}$ de $\mathrm{K}_{2} \mathrm{O}$. O canteiro experimental constou de quatro linhas de $5,0 \mathrm{~m}$, com espaçamento de $0,80 \mathrm{~m}$. Na operação de desbaste, deixaram-se cerca de sete plantas por metro linear. No primeiro ciclo (1976/77 a 1980/81), a variedade utilizada foi a IAC 18.
A adubação básica de plantio, a cada ano, constou de $10 \mathrm{~kg} / \mathrm{ha}$ de $\mathrm{Ne} 100 \mathrm{~kg} / \mathrm{ha}$ de $\mathrm{P}_{2} \mathrm{O}_{5}$, acrescida da dose correspondente de potássio. A partir do quarto ano agrícola, a dose de $150 \mathrm{~kg} / \mathrm{ha}$ de $\mathrm{K}_{2} \mathrm{O}$ passou a ser fornecida parceladamente e, depois do quinto ano, adicionou-se boro à adubação de plantio na base de $1,5 \mathrm{~kg} / \mathrm{ha}$. Sulfato de amônio, superfosfato simples, cloreto de potássio e bórax foram os produtos comerciais usados. A adubação de cobertura nos dois primeiros anos forneceu 40 $\mathrm{kg} / \mathrm{ha}$ de $\mathrm{N}$. A partir do terceiro ano agrícola, essa dose foi elevada para $50 \mathrm{~kg} / \mathrm{ha}$ de $\mathrm{N}$, mais $50 \mathrm{~kg} / \mathrm{ha}$ de $\mathrm{K}_{2} \mathrm{O}$ referentes ao parcelamento da dose máxima de potássio ( $150 \mathrm{~kg} / \mathrm{ha}$ de $\mathrm{K}_{2} \mathrm{O}$ ), aplicando-se os mesmos produtos da adubação básica.

No sexto ano agrícola (1981/82), reaplicou-se o calcário nas doses originais, passando-se a utilizar a variedade IAC 20 .

Na colheita, coletaram-se, nas duas linhas centrais de cada parcela experimental, amostras de 40 capulhos, visando aos estudos de características agronômicas e propriedades tecnológicas da fibra.

A massa de um capulho e a de cem sementes correspondem a determinações médias das massas expressas em gramas. A porcentagem de fibra representa o valor médio da sua porcentagem ponderal, obtida após o beneficiamento das amostras. Os resultados de comprimento da fibra, dados em milímetro, correspondem aos valores médios de comprimento $2,5 \%$, fornecidos pelo Fibrógrafo. A uniformidade de comprimento, expressa em porcentagem, representa a relação entre os comprimentos $50 \%$ e 2,5\%, obtidos por meio do Fibrógrafo. $O$ índice Micronaire, que representa o complexo finura + maturidade, é determinado no aparelho Fibronaire e revela a proporção do fluxo de ar que atravessa uma amostra de fibra, de $3,24 \mathrm{~g}$, sob pressão constante. A maturidade, dada em porcentagem, corresponde ao índice médio fornecido pelo Fibrógrafo, segundo método proposto por Sabino et al. (1980). A tenacidade da fibra, dada em gramas por Tex $\left({ }^{7}\right)$ é determinada no aparelho Pressley através

$\left(^{7}\right)$ g/Tex: representa a força necessária, em gramas, para romper uma mecha de fibras paralelas de título $1 \mathrm{Tcx}$. 
da ruptura de pequeno feixe de fibras paralelas, quando as garras do aparelho estão separadas de $1 / 8$ de polegada.

A avaliação estatística dos resultados baseou-se em análises conjuntas, envolvendo os dois ciclos de calagem realizados. Os efeitos das aplicações de calcário e de potássio foram decompostos nos componentes linear, quadrático e cúbico com o uso de polinômios ortogonais adequados para doses igualmente espaçadas.

\section{RESULTADOS E DISCUSSÃO}

O quadro 1 apresenta os resultados médios de características agronômicas e de propriedades tecnológicas da fibra, correspondentes às diferentes doses de calcário e de $\mathrm{K}_{2} \mathrm{O}$, assim como dados de respectivas análises da variância, obtidos nos cinco primeiros anos (1976/77-1980/81) de desenvolvimento do ensaio de longa duração em Guaíra (SP). Nesse primeiro ciclo de calagem, o calcário alterou positivamente a massa de um capulho e deprimiu a de sementes, enquanto ambas as características foram beneficiadas significativamente pela adubação potássica. A porcentagem de fibra não foi afetada pela aplicação de calcário e teve seus valores diminuídos pela ação do potássio. Quanto às propriedades tecnológicas da fibra, o comprimento, o indice Micronaire, a maturidade e a tenacidade foram deprimidos pela calagem, enquanto a adubação potássica proporcionou alguma melhoria somente na uniformidade de comprimento e índice Micronaire. Sabino (1973) observou, em ensaios de calágem e adubação mineral, efeito depressivo sobre esse indice.

O quadro 2 mostra os dados obtidos da segunda fase (1981/82-1985/86) do ensaio permanente em Guaíra (SP). Tais resultados confirmam o efeito positivo do calcário sobre a massa de um capulho e da adubação potássica nessa mesma característica e também na massa de cem sementes.

Resultados semelhantes foram obtidos por Neves et al. (1960); Fuzatto et al. (1965); Silva et al. (1974) e Carvalho (1980). Verifica-se, nesse segundo ciclo de calagem, efeito depressivo do corretivo na porcentagem de fibra, contrariando os dados de Fuzatto et al. (1965) e Carvalho (1980), mostrando melhoria nessa característica. Com relação às propriedades tecnológicas da fibra, a calagem foi tão prejudicial como na primeira fase, enquanto o uso do potássio continuou concorrendo para aumentar a uniformidade de comprimento, o índice Micronaire e a maturidade da fibra e, por outro lado, diminuir os valores de tenacidade.

O efeito positivo do potássio sobre as principais propriedades tecnológicas já foi demonstrado em diversos trabalhos (Nelson, 1949; Neves et al., 1960; Silva et al., 1971, 1974; Sabino, 1973, e Sabino \& Silva 1984).

Nos dois ciclos de calagem, não se observaram efeitos da interação calagem x adubação potássica.

Segundo Silva et al. (1994), a massa individual do capulho é determinada pelo número de lóculos existentes e pela massa de cada um deles, que depende também do número e da massa das sementes, assim como da quantidade de fibra que possui. Essa afirmação permite explicar os resultados do presente estudo, em que se verificou efeito altamente positivo do calcário sobre a massa de um capulho, contrastando com a diminuição da massa de cem sementes no primeiro ciclo de calagem e menor quantidade de fibras no scgundo ciclo. Em face do exposto, talvez a aplicação do corretivo tenha favorecido o aumento do número de sementes em cada fruto. Ainda segundo Silva et al. (1994), a perda precoce das folhas do algodoeiro impede que plantas deficientes em potássio formem adequadamente seus frutos, em especial aqueles provenientes de floradas tardias.

No presente estudo, esgotaram-se as reservas desse nutriente do solo, em função das sucessivas colheitas de algodão nas parcelas testemunhas, verificando-se a flagrante inferioridade do tratamento sem potássio no que se refere à massa de um capulho $\mathrm{e}$ à de cem sementes. Em outro trabalho, Silva et al. (1995) discutem os dados de produção obtidos no ensaio permanente, revelando o aparecimento de sintomas típicos de "fome de potássio" nas parcelas calcariadas, mas não adubadas. 


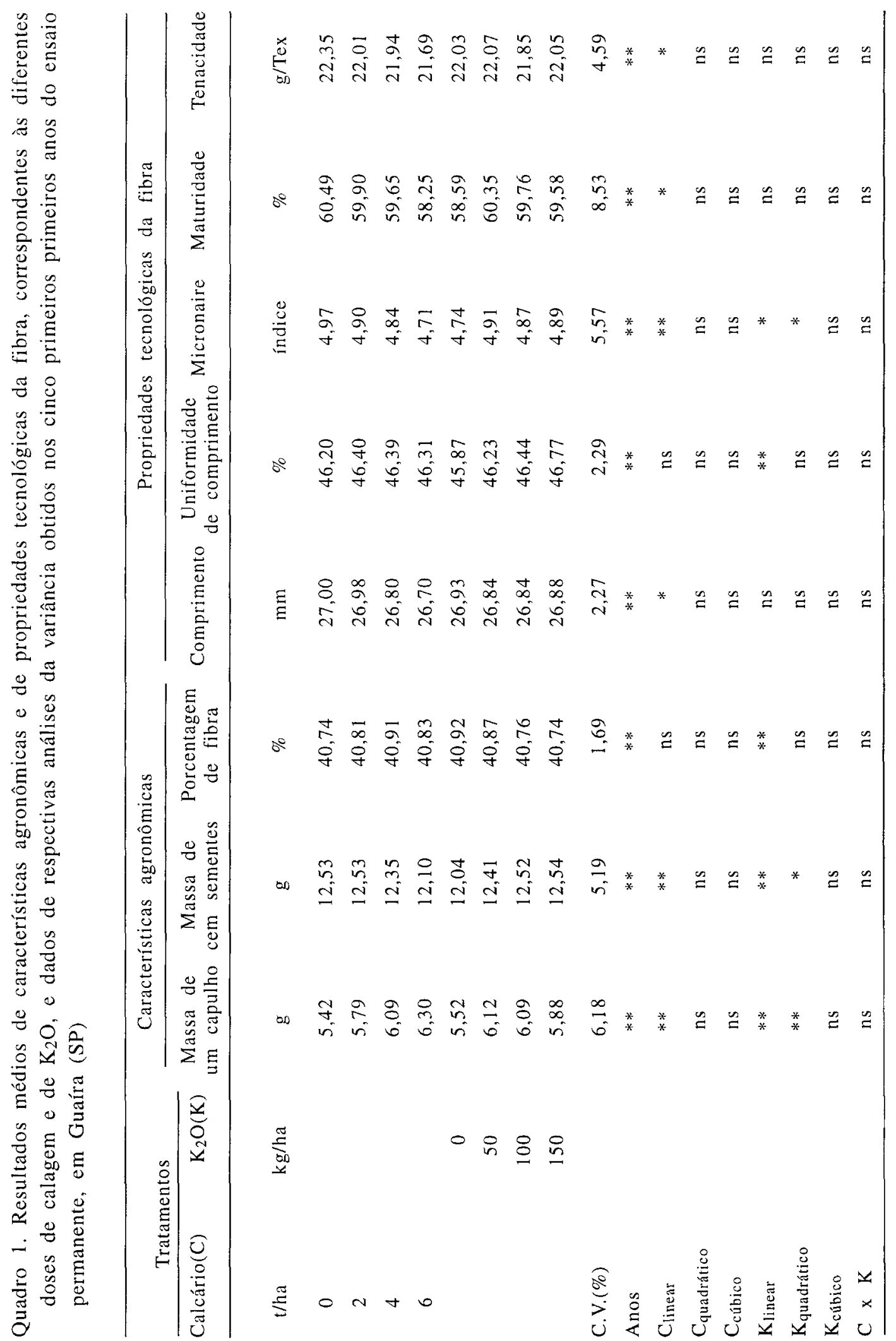




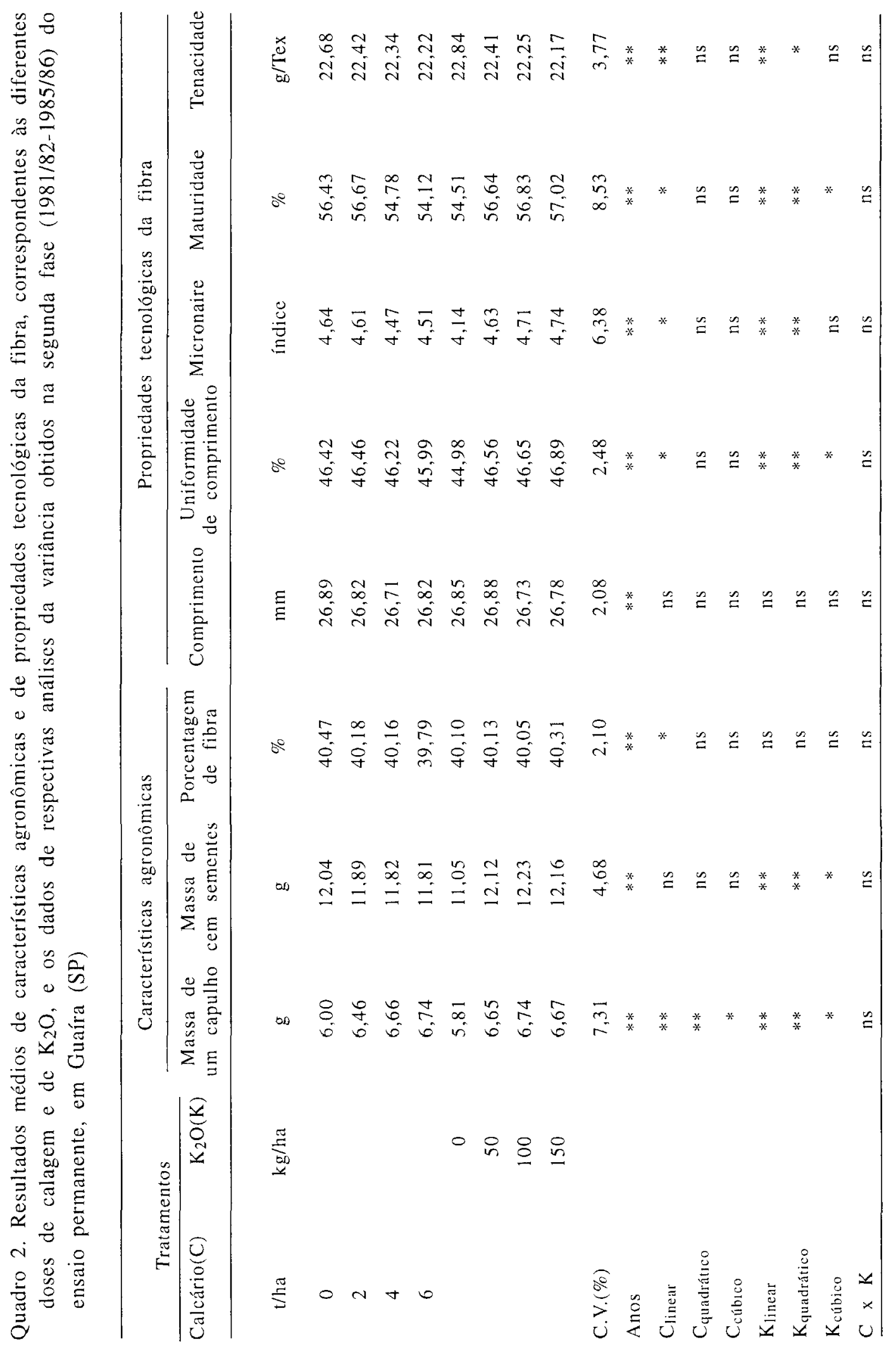


De modo antagônico à adubação potássica, a calagem contribuiu para diminuir os valores das propriedades tecnológicas estudadas, agindo de forma diferenciada daquela verificada em outros trabalhos, nos quais seu efeito negativo sempre foi diagnosticado somente para o índice Micronaire (Sabino, 1973). Segundo Fuzatto (1965), a aplicação de calcário na cultura algodoeira pode causar graves problemas, sobretudo com relação à nutrição potássica, em razão de desequilíbrios iônicos surgidos. Conforme Newman \& Sturgis (1961) as maiores necessidades de potássio para o algodoeiro poderiam ocorrer em áreas intensamente calcariadas. Embora não se tenha observado efeito signifícativo da interação calagem $x$ adubação potássica, é de esperar que a ação negativa do calcário sobre quase todas as propriedades tecnológicas estudadas se deva aos fatores mencionados.

A adubação potássica do algodoeiro, de modo geral, proporciona a manutenção da folhagem das plantas, dando condições para maior deposição de celulose nas paredes internas da fibra, pela polimerização das moléculas de glicose, refletindo em aumentos sensiveis no índice Micronaire e na maturidade. Wadleigh (1944) observou que a adição de potássio tem efeito altamente significativo sobre o comprimento médio das fibras, ou seja, sobre aquelas mais curtas, representadas pelo comprimento $50 \%$ obtido no Fibrógrafo, em relação às mais longas $(2,5 \%)$, ocorrendo, assim, maior uniformidade de comprimento das fibras, concordando com os resultados deste trabalho em relação ao potássio.

A tenacidade da fibra, determinada pelo aparelho Pressley, teve seus valores diminuídos em função da aplicação de potássio, no segundo ciclo de calagem. Tais resultados, relatados com freqüência na literatura (Sturkie, 1947; Nelson, 1949; Fuzatto et al., 1965, e Sabino, 1973), parecem guardar uma relação inversa com aqueles obtidos para maturidade e índice Micronaire, os quais são muito beneficiados pelo nutriente. Como demonstrou Sabino (1973), a aparente contradição pode ser explicada pelas deficiências já comprovadas do aparelho Pressley, que utiliza um feixe de fibras, o qual, após a ruptura, é pesado em balança de precisão. Tal deficiência seria sanada se fosse levado em con- sideração o número de fibras contido no mesmo feixe. Entretanto, valendo-se da sugestão proposta por Gridi-Papp et al. (1985), de correção do citado índice pela maturidade da fibra, demonstra-se que a tenacidade pode crescer com o uso de potássio. Aos dados de tenacidade dos últimos três anos do ensaio, aplicou-se a referida correção (resistência intrínseca), podendo-se conferir os resultados pela figura 1.

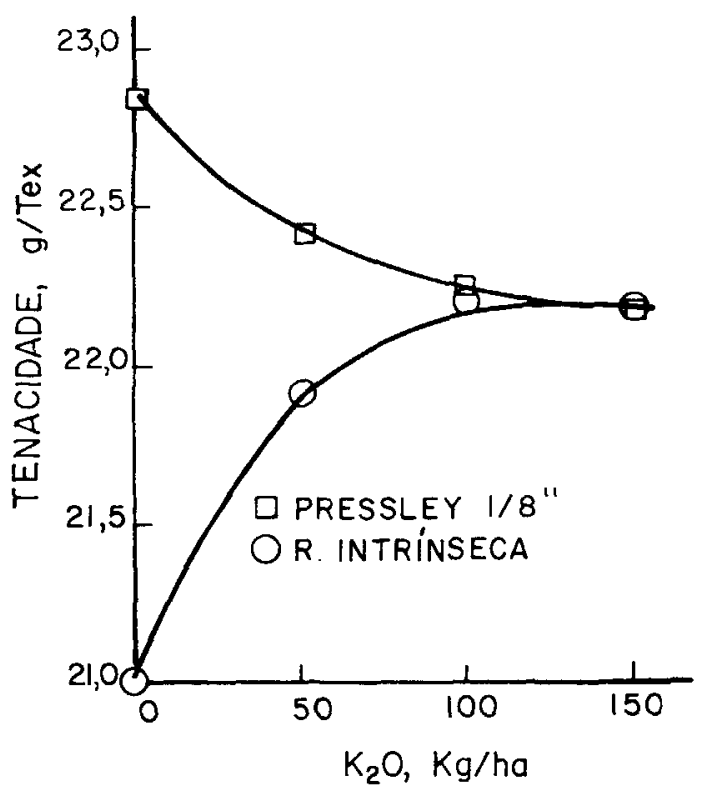

Figura 1. Variações nos valores de tenacidade da fibra, obtidos no Pressley e corrigidos para resistência intrínseca, devidas às doses de $\mathrm{K}_{2} \mathrm{O}$.

\section{CONCLUSÕES}

1. A aplicação do calcário concorreu para elevar os valores da massa de um capulho nos dois ciclos de calagem, não afetou a massa de sementes e o comprimento da fibra, na primeira fase, e a uniformidade de comprimento na segunda, e deprimiu as outras características agronômicas e propriedades tecnológicas da fibra do algodoeiro.

2. A adubação potássica elevou os valores da massa de um capulho e da massa de cem sementes, assim como da uniformidade de comprimento e índice Micronaire nos dois ciclos de calagem e da 
maturidade, na segunda fase. Melhorou também a tenacidade, quando os valores obtidos no aparelho Pressley foram corrigidos para resistência intrínseca, que expressa melhor a resistência média por fibra individual.

3. Nem mesmo com a reaplicação do calcário, a interação calcário $x$ potássio atingiu níveis de significância estatística, em dados de características agronômicas do algodoeiro e de propriedades tecnológicas da fibra.

\section{REFERÊNCIAS BIBLIOGRÁFICAS}

CARVALHO, L.H. Efeitos da calagem e da adubação boratada sobre o algodoeiro (G. hirsutum L.) cultivado em latossolo vermelho amarelo - fase arenosa. Piracicaba, 1980. 64p. Tese (Mestrado) - Escola Superior de Agricultura "Luiz de Queiroz", 1980.

CHRISTIDIS, B.G. \& HARRISON, G.J. Nutritive requirements. In: Cotton growing problems. New York, McGraw-Hill, 1955. p.191-203.

FUZATTO, M.G. Adubação mineral. In: Cultura e adubação do algodoeiro. São Paulo, Instituto Brasileiro da Potassa, 1965. p.475-508.

FUZATTO, M.G.; SILVA, N.M. \& CORREAA, F.A. O efeito das fertilizações nas características do produto do algodoeiro. In: REUNIÃO ANUAL DA S.B.P.C., 7, Belo Horizonte, 1965. Resumos, 1965. p.198199.

GRIDI-PAPP, I.L.; KONDO, J.I.; SABINO, N.P. \& FUZATTO, M.G. Resistência intrínseca da fibra de algodão determinada através da correção do índice Pressley. Bragantia, Campinas, 44(2):587-598, 1985.

NELSON, W.L. The effect of nitrogen, phosphorus and potash on certain lint and seed properties of cotton. Agronomy Journal, Madison, 41(7):298-293, 1949.

NEVES, O.S.; CAVALERI, P.A.; ABRAMIDES, E. \& FREIRE, E.S. Adubação do algodoeiro. X. Ensaios com diversos adubos potássicos. Bragantia, Campinas, 19(12):183-200, 1960.

NEWMAN, B.E. \& STURGIS, M.B. Interactions of limes and fertilizers and their effects on the yield of cotton. Baton Rouge, Louisiana Agricultural Experimental Station. Department of Agronomy, 1961. 45p. (Report of Projects)
SABINO, N.P. Efeitos da aplicação de calcário, fósforo e potássio na qualidade da fibra do algodoeiro (Gossypium hirsutum L.) cultivado em latossolo roxo. Piracicaba, 1972. 65p. Tese (Doutorado) - Escola Superior de Agricultura "Luiz de Queiroz", 1973.

SABINO, N.P.; KONDO, J.I, \& CARNEIRO, J.B. Maturidade da fibra de algodão determinada pelo Fibrógrafo Modelo 430. Bragantia, Campinas, 39:66-77, 1980.

SABINO, N.P. \& SILVA, N.M. Efeito da utilização de mistura de adubos com ou sem enxofre na precocidade e nas características do capulho e da fibra do algodoeiro. Bragantia, Campinas, 43(1):87-94, 1984.

SCHIMIDT, W.; FUZATTO, M.G. \& FREIRE, E.S. Adubação do algodoeiro. XII. Quatro experiências com $\mathrm{N}, \mathrm{P}$ e $\mathrm{K}$ em terra roxa. Bragantia, Campinas, 21(47):827-840, 1962.

SILVA, N.M. Acidez do solo e calagem para o algodoeiro. In: REUNIÃO BRASILEIRA DE FERTILIDADE DO SOLO, 15., Campinas, 1982. Anais. Campinas, Sociedade Brasileira de Ciência do Solo, 1983. p.259-276.

SILVA, N.M.; CARVALHO, L.H. \& QUAGGIO, J.A. Aplicação anual de cloreto de potássio e periódica de calcário na cultura algodoeira. Bragantia, Campinas, 54(2):353-360, 1995.

SILVA, N.M.; FERRAZ, C.A.M.; GRIDI-PAPP, I.L.; CIA, E. \& SABINO, N.P. Efeitos da aplicação de $\mathrm{N}$ e $\mathrm{K}$ sobre características gerais do algodoeiro cultivado em latossolos não deficientes em potássio. Bragantia, Campinas, 33(13):129-138, 1974.

SILVA, N.M.; FUZATTO, M.G. \& SABINO, N.P. $A d u-$ baçāo do algodoeiro em latossolos roxos altamente deficientes em potássio. Campinas, Instituto Agronômico, 1971. 15p. (Projeto BNDE/ANDA/CIA - Publicação, 6)

SILVA, N.M.; KONDO, J.I. \& SABINO, N.P. Importância da adubação na qualidade do algodão e outras plantas fibrosas. In: SIMPÓSIO SOBRE A IMPORTÂNCIA DA ADUBAÇÃO NA QUALIDADE DOS PRODUTOS AGRÍCOLAS, 1., Ilha Solteira, 1989. Anais. São Paulo, Icone, 1994. p.189-215.

STURKIE, D.G. Effects of some environmental factors on the seed and lint of cotton. Birminghan, Agricultural Experimental Station, 1947. 87p. (Bulletin, 263)

WADLEIGH, C.H. Growth status of the cotton plant as influenced by the supply of nitrogen. Little Rock, Agricultural Experimental Station, 1944. 138p. (Bulletin, 446) 